\title{
Mode choice model analysis between ridesouring and ridesplitting service in DKI Jakarta
}

\author{
Anggit Cahyo ${ }^{1, *}$, Nahry $^{1}$, and Helen Burhan ${ }^{1}$ \\ ${ }^{1}$ Department of Civil Engineering, Faculty of Engineering, University of Indonesia, Depok, Jakarta \\ ${ }^{2}$ Department of Mathematics, Faculty of Mathematics and Natural Sciences, University of Indonesia, Depok, Jakarta
}

\begin{abstract}
Beside the ridesoucing service, ridesplitting service is also offered by Transport Network Companies (TNC). The ridesplitting service have more benefit than ridesourcing because it is using the concept of carsharing. The current condition for ridesplitting service is not popular and only have small demand than ridesourcing service. This study aims to establish a mode choice model between ridesourcing and ridesplitting service in DKI Jakarta and to estimate the potential of demand shifting from ridesourcing to ridesplitting service in DKI Jakarta. The mode choice model is developed from binary logit model with stated preference survey using fare saving, additional time travel and security presented by gender parameter of ridesplitting service. the sensitivity of logit model show that highest sensitivity rate to increase mode switching to ridesplitting service is in $20 \%$ to $50 \%$ fare saving level. The probability of current condition to switch to ridesplitting service is $20 \%$.
\end{abstract}

\section{Introduction}

With traffic congestion increase in urban areas, considering how to switch private car to public transit for travelers and increase transit share becomes more and more important (Ory et al. 2004). In big cities, to encourage the use of public transport, some push and pull policies are applied such as increasing parking cost and fuel cost and transit time reduction (Habibian, 2011)

The existence of the Transport Network Companies (TNC) made people switching to ridesourcing instead of public transport. Ridesourcing is an app-based transport service links between passengers and drivers to make a reservation and payment online (1). Ridesourcing is form of transport to provide transportation-based demand for services travel where passengers looking for services through the application of smart phone of passenger vehicle personal driven by the driver non-professional their own (Victor 2015). Ridesourcing is different with ridesharing which is part of the shared mobility, the type of transportation whisch "give acces to sharing the transportation to all other passenger in short time (One Earth, 2015). Ridesourcing services easily become very popular because ease that is offered .Transportation in an ecosystem, ridesourcing demands that they had previously not served comfortably namely urban travel between the location (Rayle , 2014 ) .In addition, ridesourcing services did not only as a replacement for travel by public transport over long distances, but an important complement ( the travel feeder public transportation and be pengubung in first / last mile journey ( Shaheen, 2014 .Greencaltrain.com , 2015 )

In addition, ridesourcing services also consistently to give time to wait the lower and the costs to transport the cheaper conventional ( Zhen chen of a taxi , 2015) .Ridesourcing users now had an enormous advantage for the additional time during which use the services biasanyadigunakan for driving, and replaced be a good time more productive ( received the phone call, writing, sending email, read ) (Carranza et al , 2016 )

After presenting ridesourcing services, the company also thrown up a service ridesplitting transportation network. Ridesplitting is defined as a form of ridesourcing where passengers with origin and destination adjacent paired with the same vehicle and travel together with the reduction of the transport cost (Shaheen et al, 2016).

Ridesplitting is the concept ridesharing that is implanted on a system of ridesourcing.Users will paired with other users have in common origin and destination. The fee charged to passengers also cheaper.Ridesplitting have the potential for based on the research, more than $95 \%$ travel taxi be merged to the impact of at least to passengers comfort.(Santi, 2014 )

One of ridesplitting providers, Uberpool, showed that in san francisco, the level of in common the course of marina toward office areas much as $90 \%$ during peak hours .(Myhrvoid , 2016 ) .The supply of ride-splitting make ridesourcing become more was economical and can compete with public transport in terms of time and the

\footnotetext{
*Corresponding author: anggitcahyo61@ui.ac.id
} 
cost of .(feigon , 2016 ) .It is shown that ridesplitting could be one of a commuter transport alternative. In this study we will estimate the potential of mode shifting to ridesplitting service.

\subsection{Ridesplitting service in DKI Jakarta}

There were two ridesplitting service provider that have operated in DKI Jakarta. The first one is Uberpool, rideplitting service provided by Uber. Uberpool service has been around since Mei 2016, The rideplitting service present after the reguler service, UberX, two year after Uber service operated in Jakarta. Uberpool claimed their ridesplitting service could reduce the fare up to 25 percent.

The other ridesplitting service is Grabshare provided by Grab. The Grabshare service has been around since March 2017. Grabshare claimed their ridesplitting service could reduce cost up to $50 \%$.

Ridesplitting service's fare saving conditions in DKI Jakarta based on the survey result can be seen in the Table 1 below. The ridesplitting fare saving is only in level $10 \%$ even in the description on the operator is up to $25 \%$ or even $50 \%$. For the study below we will use the ten percent fare saving level as base value.

Table 1. Ridesourcing service conditions based on survey result

\begin{tabular}{cccccc}
\hline \multicolumn{2}{c}{ Distance } & Ridesourcing & Ridesplitting & $\begin{array}{c}\text { Fare } \\
\text { Saving }\end{array}$ & (\%) \\
\hline 14.7 & $\mathrm{~km}$ & $\mathrm{Rp} 49000.0$ & $\mathrm{Rp} 44000.0$ & $\mathrm{Rp} 5000.0$ & $10.20 \%$ \\
18.2 & $\mathrm{~km}$ & $\mathrm{Rp} 73500.0$ & $\mathrm{Rp} 66000.0$ & $\mathrm{Rp} 7500.0$ & $10.20 \%$ \\
26.2 & $\mathrm{~km}$ & $\mathrm{Rp} 118500.0$ & $\mathrm{Rp} 106500.0$ & $\mathrm{Rp} 12000.0$ & $10.10 \%$ \\
50.3 & $\mathrm{~km}$ & $\mathrm{Rp} 169000.0$ & $\mathrm{Rp} 152000.0$ & $\mathrm{Rp} 17000.0$ & $10.10 \%$ \\
\hline
\end{tabular}

\section{Research methodology}

\subsection{Approach study}

To produce mode choice model between ridesourcing and ridesplitting service, this study used binomial logit model based on discrete choice model. Data used in the model is collected with survey using stated preference method. The hypothetical condition in the survey is created by combination of controlled independent variable.

\subsection{Determination of observation variable}

The mode choice between ridesourcing service and ridesplitting is influenced by fare saving, extra time, and security based on the previous survey. The security factor is defined by the comfortable rate of sharing with stranger which is different for man and woman. Therefore, the estimation of the potential for demand switching from ridesourcing service to ridesplitting service in DKI Jakarta in this study will consider the variables of fare saving, extra time, and security.

\subsection{Data collection}

Data collection in this research is obtained by conducting an online survey which target ridesourcing user as the responden. The survey method was stated preference survey which offered hypothetical condition to the responden to choose. The scenario used including the combination of fare saving and extra time. The extra time condition were described by additional travel time from 10, 20 and 30 minutes. The fare saving conditions were illustrated with saving travel cost from 10\%, 20\%, 30\% and $40 \%$ maximum as stated by the operator. Respondents were asked about willingness to move from private vehicle to ridesourcing service based on hypotetical conditions made that can be seen in Table 2 below.

Table 2. Hypotetical condition of stated preference survey in this research

\begin{tabular}{rccc}
\hline No. & $\begin{array}{c}\text { Fare } \\
\text { saving } \\
(\mathbf{\%})\end{array}$ & $\begin{array}{c}\text { Extra } \\
\text { time } \\
\text { (minute) }\end{array}$ & $\begin{array}{c}\text { Willingness to } \\
\text { Move } \\
\text { Ridesplitting }\end{array}$ \\
\hline $\mathbf{1}$ & 10 & 30 & Yes / No \\
$\mathbf{2}$ & 10 & 20 & Yes / No \\
$\mathbf{3}$ & 10 & 10 & Yes / No \\
$\mathbf{4}$ & 20 & 30 & Yes / No \\
$\mathbf{5}$ & 20 & 20 & Yes / No \\
$\mathbf{6}$ & 20 & 10 & Yes / No \\
$\mathbf{7}$ & 30 & 30 & Yes / No \\
$\mathbf{8}$ & 30 & 20 & Yes / No \\
$\mathbf{9}$ & 30 & 10 & Yes / No \\
$\mathbf{1 0}$ & 40 & 30 & Yes / No \\
\hline
\end{tabular}

\subsection{The model}

The model in this research is specified to as a binary logit model and based on discrete choice model. Discrete choice model is a model where the function is used to find the probability of an individual to determine a choice of some alternatives based on socio-economic characteristics and the relative attractiveness of an options. This model will be representing the decision making of an individual towards some modes choice that will be used by the individual through the function called utility function. Assuming that the utility function is linear, the utility difference is expressed in the form of the difference in a number of relevant ' $n$ ' attributes between the two options. The difference utility function is specified as follows:

$$
\begin{aligned}
& U_{i}-U_{j}=\beta_{0}+\beta_{1}\left(X_{1 i}-X_{1 j}\right)+\beta_{2}\left(X_{2 i}-X_{2 j}\right)+ \\
& \cdots+\beta_{n}\left(X_{n i}-X_{n j}\right)
\end{aligned}
$$

Where $U_{i}-U_{j}$ is the utility difference between mode-i and mode- $\mathrm{j}, \beta_{0}$ is alternative specific constant (ASC), $\beta_{1}, \beta_{2}, \beta_{n}$ is coefficient of each attribute, $X_{1 i}, X_{2 i} X_{n i}$ is the variables observed for mode-i, and $X_{1 j}, X_{2 j}, X_{n j}$ is the variables observed for mode-j. The pobability that mode $i$ and $j$ will be choosen respectively as follows:

$$
P_{(i)}=\frac{\exp \left(U_{i}-U_{j}\right)}{1+\exp \left(U_{i}-U_{j}\right)}
$$




$$
P_{(j)}=1-P_{(i)}=\frac{1}{1+\exp \left(U_{i}-U_{j}\right)}
$$

Where $P_{(i)}$ is the probability of selecting mode-i, $P_{(j)}$ is the probability of selecting mode- $\mathrm{j}$, and $U_{i}-U_{j}$ is the utility difference between mode-i and mode-j.

\section{Result and discussion}

\subsection{Proportion of respondent}

Total respondents that have been surveyed in this research is 120 respondent that can be seen in Table 3 below.

Table 3. Ridesourcing service conditions based on survey result

\begin{tabular}{|c|c|c|}
\hline $\begin{array}{c}\text { Responden } \\
\text { Characteristics }\end{array}$ & Classification & $\begin{array}{c}\text { Percentage of } \\
\text { Respondent }\end{array}$ \\
\hline \multirow{2}{*}{ Gender } & Male & $40 \%$ \\
\hline & Female & $60 \%$ \\
\hline \multirow{5}{*}{ Age } & $12-16$ years old & $0 \%$ \\
\hline & $16-22$ years old & $12 \%$ \\
\hline & $22-40$ years old & $82 \%$ \\
\hline & $40-55$ years old & $6 \%$ \\
\hline & $55-64$ yeard old & $0 \%$ \\
\hline \multirow{6}{*}{ Occupation } & Student & $20 \%$ \\
\hline & $\begin{array}{l}\text { Government } \\
\text { Employee }\end{array}$ & $24 \%$ \\
\hline & Private Employee & $38 \%$ \\
\hline & Housewife & $6 \%$ \\
\hline & Businessman & $12 \%$ \\
\hline & $\begin{array}{l}\text { Pensionary / } \\
\text { Unemployed }\end{array}$ & $0 \%$ \\
\hline \multirow{5}{*}{ Income } & $\begin{array}{l}> \\
\text { Rp7,500,000.00 }\end{array}$ & $18 \%$ \\
\hline & $\begin{array}{l}\text { Rp5,000,000.00 } \\
\text { - Rp7,500,00.00 }\end{array}$ & $38 \%$ \\
\hline & $\begin{array}{l}\text { Rp3,000,001.00 } \\
- \\
\text { Rp5,000,000.00 } \\
\text { Rp1.800,001.00 }\end{array}$ & $18 \%$ \\
\hline & $\begin{array}{l}- \\
\text { Rp3,000,000.00 }\end{array}$ & $9 \%$ \\
\hline & $\begin{array}{l}< \\
\text { Rp1 } 1,800,000.00\end{array}$ & $17 \%$ \\
\hline \multirow{4}{*}{ Purpose } & Work & $64 \%$ \\
\hline & Study & $17 \%$ \\
\hline & Bussiness & $7 \%$ \\
\hline & Others & $9 \%$ \\
\hline
\end{tabular}

\subsection{Statistics of model}

Development of the model was performed with Microsoft excel using Real Statistic Resource Pack [x] to analyze the data. As the result, the developed model shown below in tabel 5 .
The goodness of fit of the model shown with chi-Sq, R2 and Hosmer test on the table 5. The man model have goodness of fit as Chi-sq and Hosmer value under 0,05 and $\mathrm{R}^{\wedge} 2$ value under 1 . The significance of each parameter on the man model also have good p-value which is under 0,05 which mean every parameter have significance influence to the model.

The parameter in the woman model also have good pvalue under 0,05 which indicate each parameter have significance influence to the model. The woman model itself have good Chi-sq value under 0,05 and $\mathrm{R}^{\wedge} 2$ value under 1. Unfortunately, the Hosmer value for the woman model is 0,095 which is more than 0,05 . It indicates the proportion of the observation value is not similar with the predicted value.

Based on the results shown on table 5, the model utility equation can be formed. The utility model is formed by substituting the constant values $\left(\beta_{0}\right)$ and coefficients $\left(\beta_{1}, \beta_{2}\right)$ already obtained into the basic utility model. The formation of the utility model for peak hours and off-peak hours is shown in Table 6 below.

Table 6. Utility function based on passenger gender

\begin{tabular}{|c|c|c|}
\hline No. & & Utility Function \\
\hline 1 & $\begin{array}{l}\text { Male } \\
\text { Passenger }\end{array}$ & $\begin{array}{c}U_{R P}-U_{R S}=-0.71051+0.08731 X_{1} \\
-0.07490 X_{2}\end{array}$ \\
\hline 2 & $\begin{array}{l}\text { Female } \\
\text { Passenger }\end{array}$ & $\begin{array}{c}U_{R s}-U_{R p}=-0.96108+0.06847 X_{1} \\
-0.04072 X_{2}\end{array}$ \\
\hline
\end{tabular}

Where $U_{R P}-U_{R S}$ is the utility function between ridesplitting and ridesourcing, $X_{I}$ is fare saving of using ridesplitting (thousand rupiah), and $X_{2}$ is additional time of using ridesplitting (minute)

Based on the utility equation in Table 6 , information about the sign of constants and coefficients of each parameter in the utility equation can be interpreted as follows:

1. The intercept constant value in both model has a negative sign. This show that when variable $\mathrm{X} 1$ and variable $\mathrm{x} 2$ are zero, the value of ridesplitting service utility is less than ridesourcing.

2. Coefficient value of parameter $X_{I}$ in both models has positive sign $(+)$. This indicates that the higher the fare saving of ridesplitting service, the value of the utility difference will increase, so the probability of choosing the ridesplitting service will increase.

3. Coefficient value of parameter $X_{2}$ in both models has a negative sign (-). This indicates that if the additional time of using ridesplitting service is higher, the value of the utility will decrease.

Based on the utility equations that have been obtained, a binary logit model can be established by substituting the equation into the basic binary logit model equation that can be seen in Table 7 below. 
Table 5. The characteristic and parameter of the developed model

\begin{tabular}{|c|c|c|c|c|c|c|c|c|c|}
\hline \multicolumn{10}{|c|}{ Man Model Statistic } \\
\hline Paramete & & Coefficient & $\begin{array}{l}\text { Std. } \\
\text { Error }\end{array}$ & Wald & p-value & $\exp (B)$ & Chi-Sq & $\mathrm{R}^{\wedge} 2$ & Hosmer \\
\hline Intercept & $\beta_{0}$ & -0.71051 & 0.26628 & 7.11993 & 0.00762 & 0.49139 & & & \\
\hline Fare_saving & $\beta_{1}$ & 0.08731 & 0.00970 & 80.94850 & $2.31677 \mathrm{E}-19$ & 1.09123 & $3.949 \mathrm{E}-13$ & 0.21345 & 0.03392 \\
\hline Add_time & $\beta_{2}$ & -0.07490 & 0.01127 & 44.20698 & $2.95426 \mathrm{E}-11$ & 0.92783 & & & \\
\hline \multicolumn{10}{|c|}{ Woman Model Statistics } \\
\hline Paramete & & Coefficient & $\begin{array}{c}\text { Std. } \\
\text { Error }\end{array}$ & Wald & p-value & $\exp (B)$ & Chi-Sq & $\mathrm{R}^{\wedge} 2$ & Hosmer \\
\hline Intercept & $\beta_{0}$ & -0.96108 & 0.29137 & 10.87970 & 0.00097 & 0.38248 & & & \\
\hline Fare_saving & $\beta_{1}$ & 0.06847 & 0.01000 & 46.89497 & 7.48948E-12 & 1.07087 & $1.172 \mathrm{E}-12$ & 0.129815 & 0.095611 \\
\hline Add_time & $\beta_{2}$ & -0.04072 & 0.01152 & 12.48767 & 0.000409646 & 0.96010 & & & \\
\hline
\end{tabular}

Table 7. Binary logit model of man-passenger and woman passenger

\begin{tabular}{lll}
\hline No. & & Binary Logit Model \\
\hline & & $P_{R P}=\frac{e^{U_{R P}-U_{R S}}}{1+e^{U_{R S}-U_{R P}}}$ \\
& & $=\frac{e^{-0.71051+0.08731 X_{1}-0.07490 X_{2}}}{1+e^{-0.71051+0.08731 X_{1}-0.07490 X_{2}}}$ \\
& & $P_{R S}=1-P_{R P}=\frac{1}{1+e^{U_{R S}-U_{P V}}}$ \\
& $=\frac{1}{1+e^{-0.71051+0.08731 X_{1}-0.07490 X_{2}}}$ \\
& & $P_{R P}=\frac{e^{U_{R P}-U_{R S}}}{1+e^{U_{R P}-U_{R S}}}$ \\
& $=\frac{e^{-0.96108+0.06847 X_{1}-0.04072 X_{2}}}{1+e^{-0.96108+0.06847 X_{1}-0.04072 X_{2}}}$ \\
& $P_{R S}=1-P_{R P}=\frac{1}{1+e^{U_{R S}-U_{M}}}$ \\
& $=\frac{1}{1+e^{-0.96108+0.06847 X_{1}-0.04072 X_{2}}}$
\end{tabular}

Where $P_{R P}$ the probability of selecting ridesplitting, $P_{R S}$ is the probability of selecting ridesourcing, $U_{R P}-U_{R S}$ is the utility difference between ridesplitting and ridesourcing, $X_{I}$ is fare saving of ridesplitting service, and $X_{2}$ is additional time of ridesplitting service (minute).

\subsection{The Sensitivity of model}

The sensitivity graph of peak hours model and off-peak hours model can be seen in the following Figure 1 below.

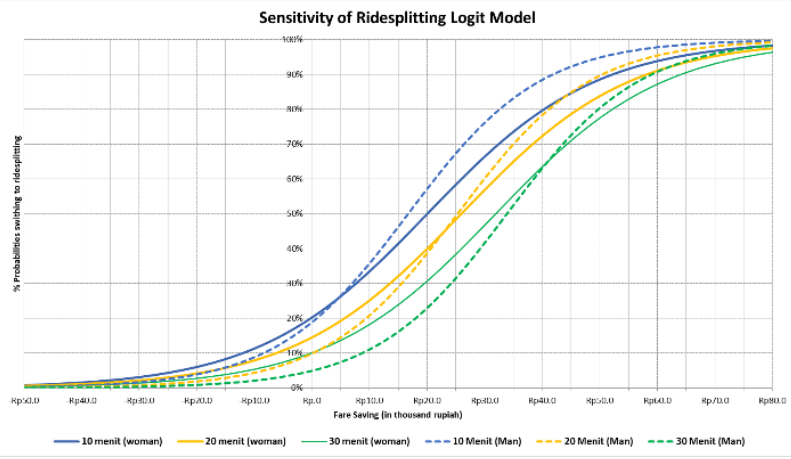

Fig. 1. Sensitivity of peak hours and off-peak hours model
In the figure 1 shown every sensitivity of every utility function from man-passenger and woman passenger with additional delay variety. The horisontal axis is the fare saving and the vertical axis is the probability of switching to ridesplitting service. The sensitivity area is shown when fare saving is from $\mathrm{Rp} 10.000$ to $\mathrm{Rp} 50.000$ for almost every utility function. But the man-pasengger utility function is more sensitive than woman-passenger utility function in every additional time series.

For the 10 minutes additional time, the probability of passenger switching to ridesplitting in 10 minutes additional time is saving $\mathrm{Rp} 20.000$. For the 20 minutes additional time, the fare saving must be in Rp 25.000 dan almost Rp35.000 for the 30 minutes additional time. The value of fare saving is simillar for man-passenger and woman passenger.

\subsection{Potential of demand shifting in current conditions}

Based on the mode choice model that has been formed, then graphs can be drawn that illustrate the potential for demand shifting from ridesourcing service to ridesplitting based on current conditions of ridesplitting service (Table 4) that can be seen in the Figure 2 below.

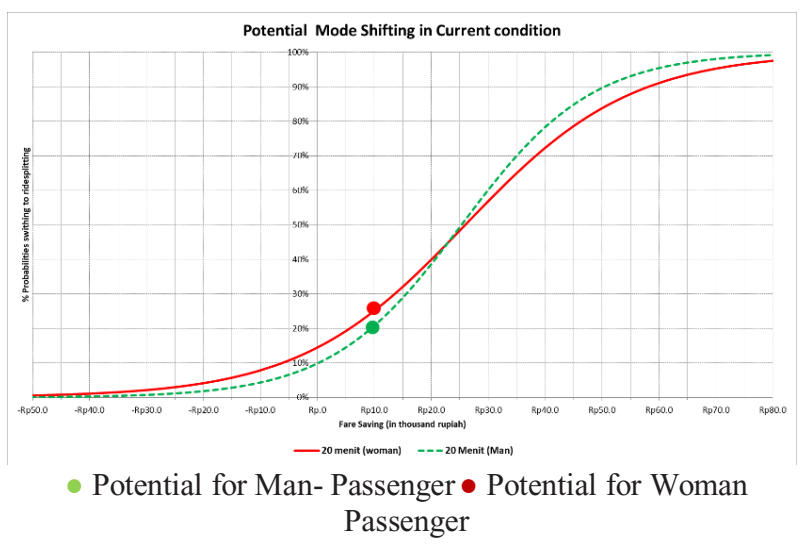

Fig. 2. Potential Of Mode Shifting In Current Conditions 
Based on Figure 2, the probabitlity for demand shifting from ridesourcing service to ridesplitting service based on current condition whish fare saving is in $10 \%$ level and average additional in 20 minute is $20 \%$ for manpassenger and $25 \%$ for woman-passenger. It is shown that the potential of mode switching in current condition is low. To increase the probability in current conditio with 20 minutes additional time, the fare saving level must increase to $\operatorname{Rp} 25.000$ or $25 \%$.

\section{Conclusion}

The mode choice model between ridesplitting service and ridesourcing service in DKI Jakarta that formed in this research is binary logit model that can be seen in Table 9 below.

Table 9. Mode choice model between ridesourcing service and private vehicle in DKI Jakarta

\begin{tabular}{clc}
\hline No. & Passenger & \multicolumn{1}{c}{ Binary Logit Model } \\
\hline 1 & $\begin{array}{l}\text { Man - } \\
\text { Passenger }\end{array}$ & $P_{R P}=\frac{e^{U_{R P}-U_{R S}}}{1+e^{U_{R S}-U_{R P}}}$ \\
& $=\frac{e^{-0.71051+0.08731 X_{1}-0.07490 X_{2}}}{1+e^{-0.71051+0.08731 X_{1}-0.07490 X_{2}}}$ \\
2 & $\begin{array}{l}\text { Woman- } \\
\text { Passenger }\end{array}$ & $P_{R P}=\frac{e^{U_{R P}-U_{R S}}}{1+e^{U_{R P}-U_{R S}}}$ \\
& $=\frac{e^{-0.96108+0.06847 X_{1}-0.04072 X_{2}}}{1+e^{-0.96108+0.06847 X_{1}-0.04072 X_{2}}}$ \\
\hline
\end{tabular}

Where $P_{R P}$ the probability of selecting ridesplitting, $P_{R S}$ is the probability of selecting ridesourcing, $U_{R P}-U_{R S}$ is the utility difference between ridesplitting and ridesourcing, $X_{I}$ is fare saving of ridesplitting service, and $X_{2}$ is additional time of ridesplitting service (minute).

The increase of fare saving level increa.sing the probability of passenger switching from ridesourcing to ridesplitting. As the additional travel time, the less the additional time, the probability of mode swithing will increase. It is shown with the negative attribut (-) for the additional time variable in the utility function.

The sensitivity of both model is simillar which is from $\mathrm{Rp} 10.000$ to $\mathrm{Rp} 50.000$. the man-passenger has more sensitivity utility function than the woman-passenger model. For the current condition, the probability of passenger switching from ridesourcing service to ridesplitting is $20 \%$ for man and $25 \%$ for woman passenger.

The authors would like to thank to DRPM UI (Directorate of Research and Community Service Universitas Indonesia) for the research grants through Hibah PITTA 2018.

\section{References}

1. L. Rayle, D. Dai, N. Chan, R. Cervero, and S. Shaheen. Just a Better Taxi? A Survey-Based Comparison of Taxis, Transit, and Ridesourcing Services in San Francisco, Transport Policy, Vol. 45, 2016, pp. 168-178 (2015)
2. C. Chavis, V.V. Gayah, Development of a mode choice model for general purpose flexible route transit systems. Morgan State University (2016)

3. C. Zhen. Impact of ridesourcing services on travel habits and transportation planning, Graduate Dissertation for Swanson School of Engineering at Beijing Jiaotong University. 7 July (2015)

4. S. Feigon, C. Murphy, Shared mobility and the transformation of public transit, Pre-publication draft of TCRP Report 188. Transportation Research Board, Washington, D.C (2016)

5. O. Khan, Modelling passenger mode choice behavior using computer aided stated preference data, Queensland University of Technology (2007)

6. E. Martin, S. Shaheen, The impacts of Car2go on vehicle ownership, modal shift, vehicle miles traveled, and greenhouse gas emissions: An analysis of five North American cities. Working Paper, Transportation Sustainability Research Center, University of California, Berkeley (2016)

7. L. Rayle, D. Dai, N. Chan, R. Cervero, and S. Shaheen, App-based, on-demand ride services: comparing taxi and ridesourcing trips and user characteristics in San Francisco. University of California Transportation Center (UCTC0 Working Paper November (2014)

8. P. Santi, G. Resta, M. Szell, S. Sobolevsky, S.H. Strogatz, C.Ratti, Quantifying the benefits of vehicle pooling with shareability networks. Proc. National Academy of Science, 111(37), 13290-13294 (2014)

9. S. Shaheen, C. Nelson, Shared Mobility:A Sustainability \& Technologies Workshop; Definition, Industry Development, and Early Understanding. Whitepaper prepared for California Departement of Transportation by UC Berkeley Transportation Sustainability Research Center. November (2015)

10. M .Wohl, and B.V. Martin, Traffic system analysis for engineers and planners. McGraw Hill, New York (1976)

11. L. Yang, C. F. Choudhury, M. Ben-Akiva, Stated preference survey for new smart transport modes and services: design, pilot study and new revision. ITS Lab Massachusetts Institute of Technology (2009)

12. J. D. Ortuzar and L. G. Wilumsen, Modelling transport (4th Edition), West Susex: Wiley, (2011) 